\title{
Real-Time Live Confocal Fluorescence Microscopy as a New Tool for Assessing Platelet Vitality
}

\author{
Martin Hermann $n^{\mathrm{a}, \mathrm{b}}$ Oliver Nussbaumer ${ }^{\mathrm{a}}$ Ralf Knöfler ${ }^{\mathrm{c}}$ Paul Hengster ${ }^{\mathrm{a}}$ \\ Walter Nussbaumer ${ }^{\mathrm{d} \#}$ Werner Streif ${ }^{\mathrm{b} \#}$ \\ ${ }^{a}$ KMT Laboratory, Department of Visceral, Transplant and Thoracic Surgery, Center for Operative Medicine, \\ ${ }^{\mathrm{b}}$ Department of Pediatrics, Innsbruck Medical University, Innsbruck, Austria \\ ${ }^{c}$ Department of Pediatrics, Carl Gustav Carus University Hospital Dresden, Germany \\ ${ }^{d}$ Central Institute for Blood Transfusion and Immunology, Innsbruck Medical University, Innsbruck, Austria
}

\section{Keywords}

Confocal microscopy - Mitochondria function tests . Blood platelets

\section{Summary}

Background: Assessment of platelet vitality is important for patients presenting with inherited or acquired disorders of platelet function and for quality assessment of platelet concentrates. Methods: Herein we combined live stains with intra-vital confocal fluorescence microscopy in order to obtain an imaging method that allows fast and accurate assessment of platelet vitality. Three fluorescent dyes, FITC-coupled wheat germ agglutinin (WGA), tetramethylrhodamine methyl ester perchlorate (TMRM) and acetoxymethylester (Rhod-2), were used to assess platelet morphology, mitochondrial activity and intra-platelet calcium levels. Microscopy was performed with a microlens-enhanced Nipkow spinning disk-based system allowing live confocal imaging. Results: Comparison of ten samples of donor platelets collected before apheresis and platelets collected on days 5 and 7 of storage showed an increase in the percentage of Rhod-2positive platelets from 3.6 to 47 and finally to $71 \%$. Mitochondrial potential was demonstrated in $95.4 \%$ of donor platelets and in $92.5 \%$ of platelets stored for 7 days. Conclusion: Such fast and accurate visualization of known key parameters of platelet function could be of relevance for studies addressing the quality of platelets after storage and additional manipulation, such as pathogen inactivation, as well as for the analysis of inherited platelet function disorders.

\footnotetext{
"Authors contributed equally.
}

\section{KARGER}

Fax +497614520714

Information@Karger.de

www.karger.com (c) 2010 S. Karger GmbH, Freiburg

\section{Schlüsselwörter \\ Konfokale Mikroskopie · Mitochondrienfunktionstests . Blutplättchen}

\section{Zusammenfassung}

Hintergrund: Die Vitalitätsbestimmung von Blutplättchen ist sowohl für die Analyse angeborener Plättchendefekte als auch für die Qualitätsbestimmung von Plättchenkonzentraten von zentraler Bedeutung. Methoden: In der vorliegenden Arbeit stellen wir eine Methode vor, die mittels einer Kombination von Vitalfarbstoffen und konfokaler "Real time»-Mikroskopie neue Einblicke in die Vitalitätsbestimmung lebender Plättchen ermöglicht. Mittels der Zugabe von FITC-gekoppeltem Weizenkeimlektin (WGA), Tetramethylrhodamin-Methylesterperchlorat (TMRM) und Acetoxymethylester (Rhod-2) wurde bei lebenden Blutplättchen deren Morphologie, mitochondriale Aktivität und Veränderungen im Calcium-Haushalt im Rahmen der Lagerung analysiert. Für die Mikroskopie wurde ein Nipkow-System gewählt, das eine konfokale Mikroskopie lebender Zellen ermöglicht. Ergebnisse: Der Vergleich von 10 humanen Blutplättchenproben zu Beginn bzw. nach 5 und 7 Tagen Lagerung zeigte einen Anstieg der Rhod-2-positiven Plättchen von 3,6 über 47 auf $71 \%$. Die Anzahl der Blutplättchen mit TMRM-positiven Mitochondrien hingegen lag vor der Lagerung bei 95,4\% und nach den 7 Tagen Lagerung bei 92,5\%. Schlussfolgerung: Die hier vorgestellte Methodik der Bildgebung zur Bestimmung vitaler Parameter von Blutplättchen eignet sich als ergänzende Analysemodalität für eine bessere Bestimmung der Blutplättchenqualität. 


\section{Introduction}

Despite being small and anucleated, platelets are big players when it comes to life-and-death decisions. They play several key roles in hemostasis and thrombosis as well as in diseases such as myocardial infarction, stroke and deep vein thrombosis. For therapeutic purposes, platelet concentrates are transfused to patients with cancer, blood disease, trauma as well as to those undergoing cardiac surgery [1]. Storage of platelet concentrates for transfusion is limited to 5-7 days because of the risk of bacterial growth [2] and the loss of platelet functionality [3]. In order to meet the increasing demand, further improvements in platelet storage techniques and quality assessment tools are needed.

The temperature at which platelets are stored $\left(22 \pm 2{ }^{\circ} \mathrm{C}\right)$ [4] and the biological composition of platelet storage concentrates as well as their media favor bacterial contamination. Cooling or refrigeration is not an alternative because, once transfused, cooled or refrigerated platelets are rapidly cleared from the circulation. At least one of the known mechanisms responsible for this clearing is von Willebrand receptor clustering, which permits recognition of platelets by hepatic macrophage complement type 3 receptors [5-7]. Therefore, platelets are routinely stored in gas-permeable bags on shaking racks at room temperature. In order to cope with one of the major problems of platelet storage, namely the aforementioned risk of bacterial contamination, there are several options for pathogen reduction. One of them is the Mirasol Pathogen Reduction Technology ${ }^{\circledR}$ (CaridianBCT, Lakewood, CO, USA) that uses riboflavin (vitamin B2) in the presence of UV light (280-360 nm) to alter the nucleic acid structure of disease-causing agents in blood products, thereby reducing the infectious pathogen load [8]. Although they are anucleated, platelets also contain DNA in the mitochondria, the key organelles where life-and-death decisions are made. Therefore, one of the questions addressed in this study is whether Mirasol pathogen reduction treatment (Mirasol-PRT) has an influence on mitochondrial function in platelets.

During storage platelets are prone to several changes such as increased activated caspase 3 levels, phosphatidylserine (PS) exposure on their cell surface, loss of sialic acid from their membrane proteins as well as the acidification of their surrounding medium due to the metabolically produced lactate. All these changes cause a progressive loss of platelet vitality and function, a phenomenon known as "platelet storage lesion' [9].

Precise and fast assessment of platelet quality/function after storage remains a critical issue [10]. Most of the tests for platelet quality are performed in vitro and hardly suitable for in vivo situations. The introduction of electron microscopy allowed new insights into platelet structure, function and pathology. Together with classical aggregometric studies, electron microscopy has helped understand, characterize and classify many inherited platelet disorders [11]. Nevertheless, many questions regarding platelet functionality and its prediction remain to be answered.

For this reason, we combined the addition of live stains and intra-vital confocal fluorescence microscopy to develop a new means of fast and accurate assessment of platelet vitality:

Although anucleated, blood platelets are highly organized mitochondria-bearing cells. At all stages of their 'life' platelets are energy-dependent. During circulation, platelets are reactive to various stimuli and selectively release the materials stored in their three different types of granules. This 'release reaction' is an important step in primary hemostasis. Energy and messengers required for physiological platelet reactivity are mainly provided by mitochondria [12].

Mitochondria are the main producers of ATP in eukaryotic aerobic cells. In addition, mitochondria are also involved in ion homeostasis, regulation of the cellular redox state, transportation of metabolites, lipid and amino acid metabolism as well as cell death. All these functions are highly dependent on the electrochemical transmembrane potential that is physiologically generated across the inner mitochondrial membrane by respiratory chain activity $[13,14]$.

A variety of methods have been developed to investigate the functionality of mitochondria. In conjunction with confocal microscopy, cell-permeable cationic fluorescent probes are widely employed to monitor mitochondrial transmembrane potential and its changes. Application of such potentialdependent probes allows the monitoring of mitochondrial membrane potentials in individual living cells as well as in large populations of cells [15-18].

Recent developments in live stains as well as in confocal technologies have enabled us to study and analyze cells in their living, non-fixed state. Such approaches have yielded great new insights into the complexities of cellular behavior. While traditional laser scanning confocal microscopes deliver excellent spatial information, data acquisition is slow and at the expense of substantial dye bleaching or, as in the case of living cells, even phototoxicity, which thus limits the use of such microscopes for the study of living cells. Modern Nipkow disk confocal microscopes avoid these limitations of speed, photobleaching and phototoxicity by illuminating the whole field of view at once using over a thousand of 'microbeams', as opposed to a single point exciting each part of the sample over the space of several hundredths of a second. As a result, Nipkow disk confocal microscopy allows fast acquisition of data with high spatial resolution in living cells [19].

This study describes a simple, very accurate and fast (therefore the name 'real time') method for a better assessment of platelet quality that combines the advantages of microlensenhanced Nipkow disk-based confocal microscopy (U1traVIEW RS; Perkin Elmer) with that of fluorescent dyes for visualizing platelet morphology (FITC-coupled wheat germ agglutinin (WGA); Molecular Probes), time-dependent mitochondrial membrane potentials (tetramethylrhodamine me- 
thyl ester perchlorate (TMRM); Sigma-Aldrich) and calcium levels (cell-permeable acetoxymethylester (Rhod-2); Molecular Probes).

\section{Material and Methods}

\section{Platelet Collection}

Platelet collection was performed as previously described [20]. In brief, double-dose apheresis platelet components were collected from normal volunteer donors using a blood cell separator (Amicus, Baxter Healthcare Corp., Deerfield, IL, USA). Platelet components were in-process leukoreduced to levels of fewer than $10^{6}$ white blood cells during collection. Each platelet collection consisted of approximately $6 \times 10^{11}$ platelets suspended in $570 \mathrm{ml}$ of $37 \%$ plasma and $63 \%$ Intersol (platelet additive solution, Baxter Healthcare Corp., La Châtre, France). Platelet concentrates were kept at a constant temperature of $22^{\circ} \mathrm{C}$ in a platelet incubator (Helmer PF96, Noblesville, IN, USA) for 7 days.

\section{Mirasol Pathogen Reduction Treatment}

The double-dose platelet units were split; one unit was treated with riboflavin solution $(35 \mathrm{ml})$ and $\mathrm{UV}$ light, the other unit was left untreated. Units were stored for up to 7 days under standard blood banking conditions (as described above), and samples were obtained with sterile couplers.

\section{Staining Procedure}

For real-time live confocal imaging analysis a 1-ml sample was taken from each platelet collection using a sampling site coupler. Live staining was performed in 8-well-chambered coverglasses (Nalge Nunc International, Rochester, NY, USA). For this purpose $200 \mu \mathrm{l}$ of the platelet suspension was incubated in the dark for $20 \mathrm{~min}$ at room temperature.

\section{Real-Time Live Confocal Fluorescence Microscopy}

Three fluorescent dyes, FITC-coupled WGA (final working concentration $5 \mu \mathrm{g} / \mathrm{ml}$; Molecular Probes, Eugene, OR, USA), Mitotracker Green (MTG, final working concentration $100 \mathrm{nmol} / \mathrm{l}$, Molecular Probes), TMRM (final working concentration $100 \mathrm{nmol} /$; Sigma-Aldrich, St. Louis, MO, USA) and cell-permeable acetoxymethylester (Rhod-2; final concentration $5 \mu \mathrm{mol} / \mathrm{l}$; Molecular Probes) were used according to the manufacturers' instructions to assess either platelet morphology, mitochondrial morphology, mitochondrial membrane potentials or platelet calcium content. The membrane potential-independent mitochondrial dye MTG was used as a control to verify mitochondrial origin of the TMRM fluorescence.

Confocal microscopy was performed with a microlens-enhanced Nipkow disk-based confocal system UltraVIEW RS (Perkin Elmer, Wellesley MA, USA) mounted on an Olympus IX-70 inverse microscope (Olympus, Nagano, Japan). Excitation of WGA and MTG was achieved by using the $488 \mathrm{~nm}$ line, with the resulting fluorescent wavelengths observed using a $500 \mathrm{~nm}$ long-pass filter. TMRM fluorescence was excited with the $568 \mathrm{~nm}$ line, and emission was collected using a $600 \pm 20 \mathrm{~nm}$ bandpass filter. Light was collected through a $100 \times 1.4$ numerical aper-

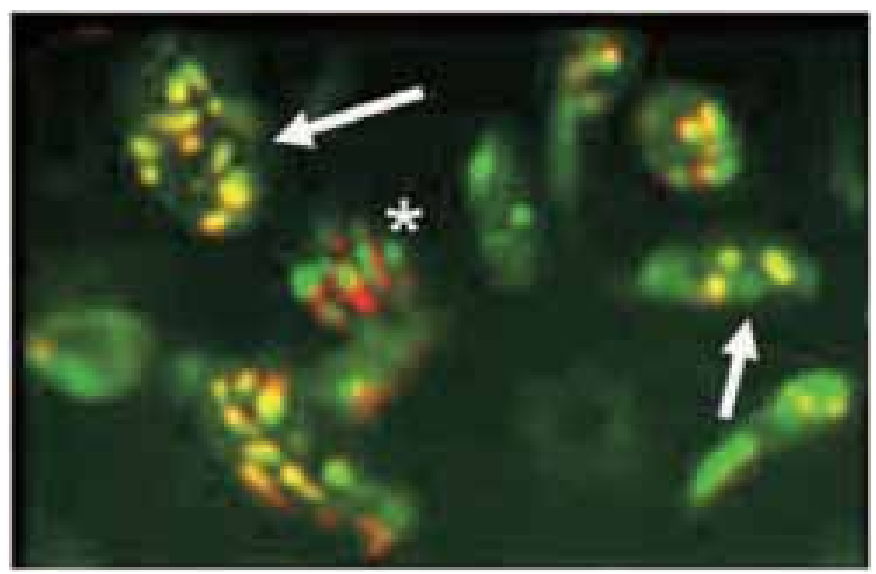

Fig. 1. Staining of human platelets with TMRM (red) and MTG. The co-localization resulting in a yellow stain (see arrows) documents the mitochondria-specific TMRM fluorescence. The non-overlapping stain in the platelet marked with an asterisk is due to its movement during image acquisition. Shown is one confocal plane, image acquisition time is $800 \mathrm{~ms}$ per wavelength, objective: $100 \times$ oil immersion with a numerical aperture of 1.4 .
Fig. 2. Real-time live confocal microscopy of human platelets stained with Rhod-2 (red, top row), TMRM (red, bottom row) and WGA (green) after 7 days of storage under standard conditions (top: A merge, B WGA, C Rhod-2, bottom: $\mathbf{D}$ merge, E WGA, F TMRM) Shown are z-stacks of four planes with a slice spacing of $1 \mu \mathrm{m}$. Images were acquired using a $100 \times$ oil objective with a numerical aperture of 1.4 ; bar $=$ $2 \mu \mathrm{m}$. The stacks were created using the 3D software 'Volocity' from Perkin Elmer.
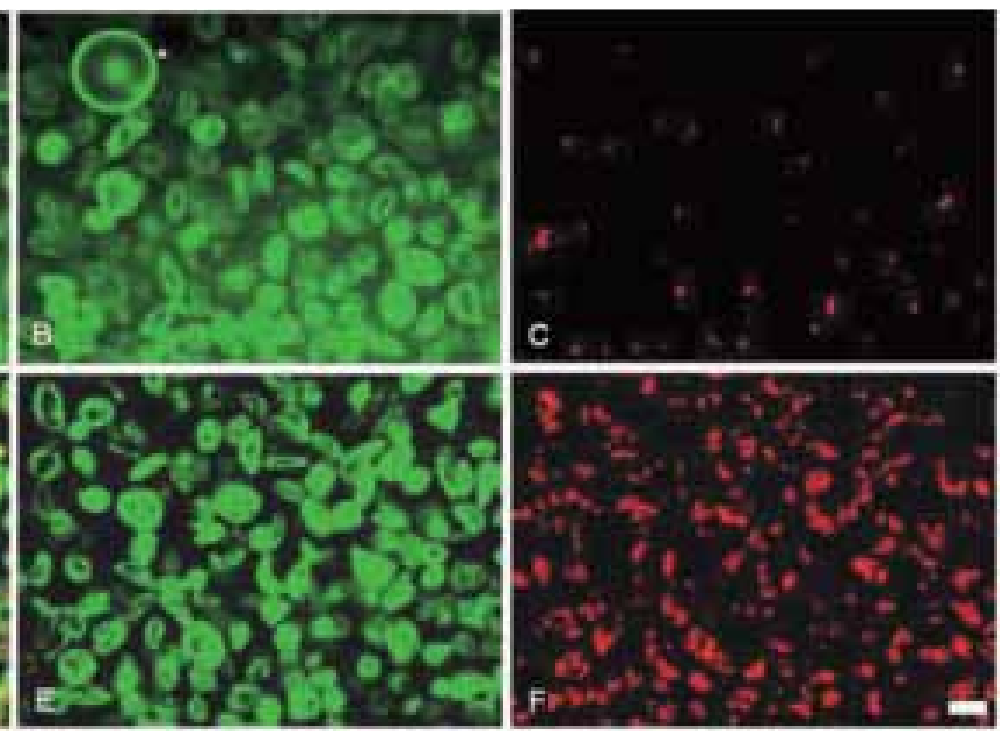
ture oil immersion objective, and images were captured with a cooled digital CCD camera (Hamamatsu Photonics K.K., Hamamatsu City, Japan) in combination with the UltraVIEW RS or the 3D software 'Volocity' from Perkin Elmer.

\section{Statistics}

Data are presented as means \pm standard deviation. Statistical differences among groups were measured with the paired Student's t-test. Significance was determined at the $\mathrm{p}<0.05$ level.

\section{Results}

As shown in figure 1, confocal live co-staining of human platelets with reduced MTG in combination with TMRM demonstrates mitochondrial origin of the TMRM staining visualized by the yellow color. Non-overlapping signals were caused by movement of some platelets during image acquisition. Nevertheless, the acquisition time of $800 \mathrm{~ms}$ per wavelength is short enough to visualize single mitochondria in individual live platelets. The number of active mitochondria visualized via TMRM fluorescence varies among individual platelets (fig. 1, 2, 3).

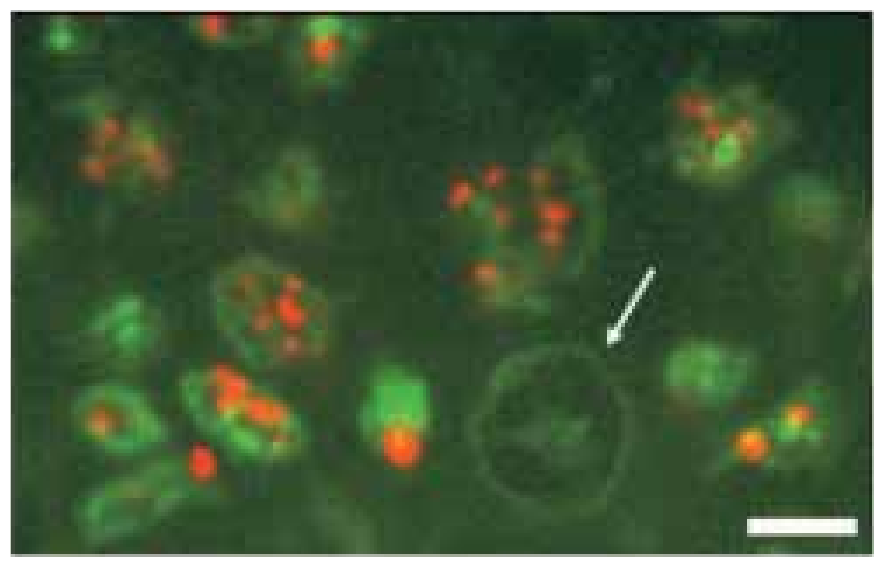

Fig. 3. Live confocal imaging of human platelets stained with TMRM (red) and WGA (green) after 7 days of storage under standard conditions. Note the absence of a TMRM fluorescence in the therefore nonviable platelet (see arrow). Objective: $100 \times$ oil immersion with a numerical aperture of $1.4 ; \mathrm{bar}=2 \mu \mathrm{m}$. See also video 1 at http://content.karger.com/ ProdukteDB/produkte.asp?doi=320368.
Fig. 4. Comparing ten samples of donor platelets collected before apheresis and platelets collected on days 1, 5 and 7 of storage showed an increase in the percentage of RHOD-2positive platelets starting from $3.6 \%$ (day 0 ) to $50 \%$ (days 1 and 5 ) and $71 \%$ (day 7). Mitochondrial potential was demonstrated in $95.4 \%$ of donor platelets and in $92.5 \%$ of platelets stored for 7 days.

Additional manipulation (pathogen inactivation; Mirasol) increased the percentage of RHOD-2-positive cells to $79.5 \%$ and decreased the percentage of platelets with demonstrable mitochondrial potential to $67 \%$ after 7 days of storage. Significant results $(\mathrm{p}<0.05$, see Rhod2 measurements comparing day 0 with day $1 / 5 / 7)$ are visualized with an asterisk.

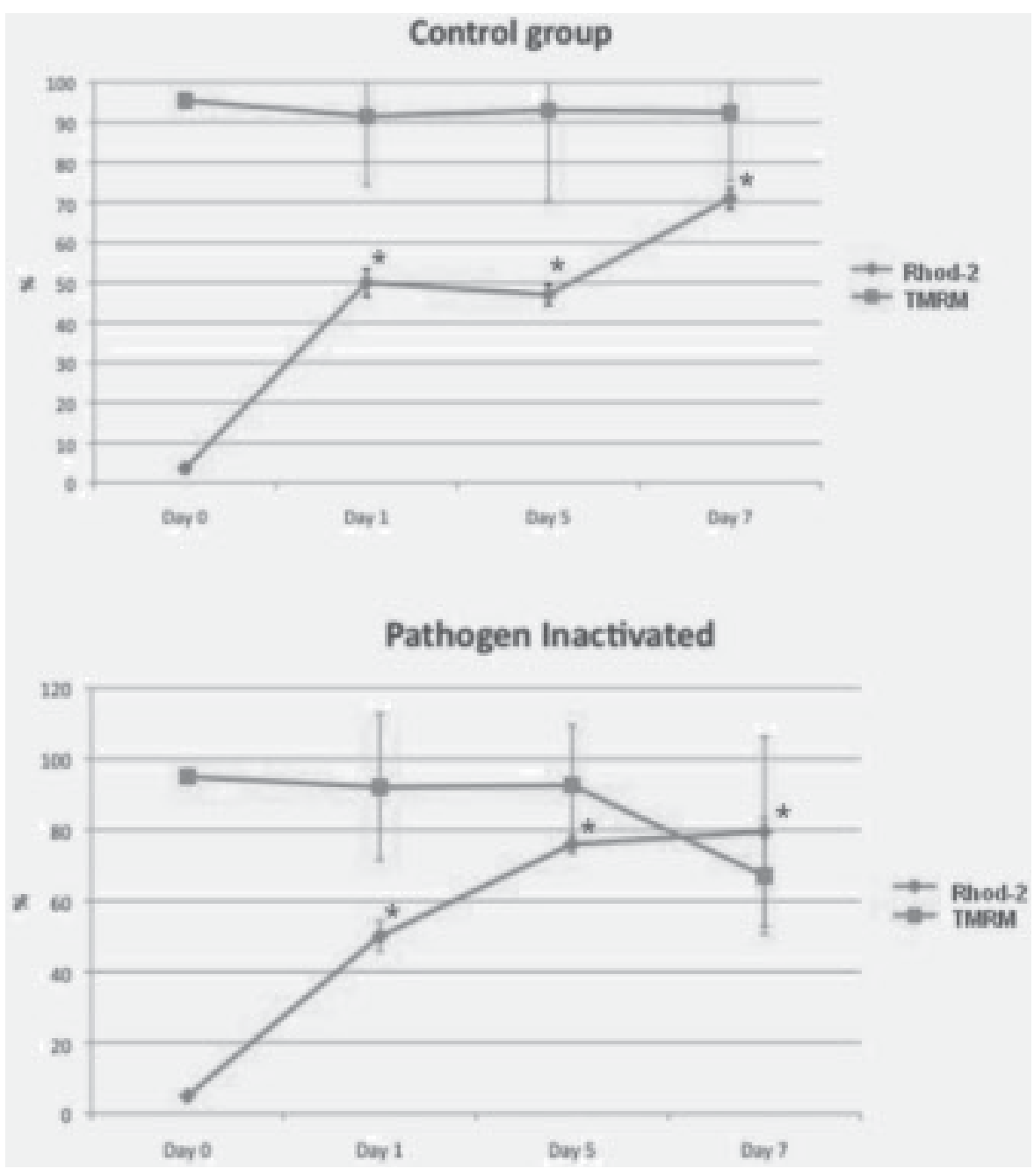


To visualize platelet morphology, we used FITC-coupled WGA that binds to $\mathrm{N}$-acetylglucosamine and $\mathrm{N}$-acetylneuraminic acid residues and thereby stains the outer membrane of the platelets. In combination with TMRM it is possible to visualize platelet morphology as well as the individual functional mitochondrial state of the platelet (fig. 1, 2, 3; see also video 1 and video 2 (WGA-green staining, TMRM-red staining) which are available online at http://content.karger. com/ProdukteDB/produkte.asp?doi=320368. Video 1 shows a time series in one plane and video 2 shows the $\mathrm{z}$-axis through one platelet).

Using a combination of Rhod-2 and WGA permits increased calcium levels to be identified within individual platelets (fig. 3). While the red signal in the case of TMRM demonstrates viability, Rhod-2 staining shows a stress reaction within platelets.

In order to analyze whether platelet storage or their pathogen inactivation affects the staining pattern of the platelets when using WGA, TMRM and Rhod-2, ten apheresis donations were split into two groups. One group was stored for 7 days without any additional treatment, the other was pathogen-inactivated using the riboflavin-based MIRASOL-PRT system. On days 0,5 and 7 , samples were taken and analyzed using real-time live confocal microscopy in combination with the afore-mentioned live stains.

Comparison of the ten samples of donor platelets collected before apheresis and platelets collected on days 5 and 7 of storage showed an increase in the percentage of Rhod-2-positive platelets, namely from 3.6 to 47 and finally to $71 \%$ (before vs. on day 5 vs. day 7). Mitochondrial potential was demonstrated in $95.4 \%$ of donor platelets and in $92.5 \%$ of platelets stored for 7 days.

Additional manipulation (pathogen inactivation) increased the percentage of Rhod-2-positive cells to $79.5 \%$ and decreased the percentage of platelets with demonstrable mitochondrial potential to $67 \%$ after 7 days of storage. Both values are compared to the values of the nontreated platelets and are not significant (fig. 4).

\section{Discussion}

Platelets, the smallest cellular elements in circulating blood $(2.5 \times 0.5 \mu \mathrm{m})$, are anucleated and originate from the cytoplasmic fragmentation of megakaryocytes. Due to their small size and lack of a nucleus, the evaluation and analysis of platelet vitality remains a greater challenge than that of nucleated cells. For eukaryotic nucleated cells viability is often documented using fluorescent DNA-binding stains such as propidiumiodide which are excluded by living cells due to their intact cell membrane, whereas in dead cells this barrier is lost. Nonviable cells can therefore be easily visualized due to their nuclear fluorescence. For platelets, being anucleated, such viability staining methods are not suitable. The aim of this study was therefore to establish a new method allowing a fast and accurate analysis of platelet viability. For this purpose we combined the addition of live stains with real-time confocal fluorescence microscopy in order to obtain a method allowing a fast and accurate assessment of platelet viability.

The advantage of the 'real-time' live confocal imaging relies in its precision, accuracy and high speed (real time) of data acquisition. Therefore, in spite of the small size of human platelets and their permanent movement within the sample we were still able to visualize individual active mitochondria within single platelets. These data or images are acquired within milliseconds and are immediately available for further analysis.

The precise assessment of vitality following storage is mandatory because of the known platelet storage lesions [21] that can contribute to serious adverse posttransfusion events such as potentially fatal transfusion-related acute lung injury (TRALI) or multiorgan failure [22, 23]. With the aim to limiting transfusion-transmitted infections, several pathogen reduction methods can be used for the stored platelet concentrates [24]. Such treatments might potentially exert an influence on platelet vitality, and therefore there is a great need to better analyze and understand platelet function. This is true especially in view of very recent findings indicating that platelets have a previously unrecognized capacity to produce functional progeny; this capacity involves a form of cell division that does not require a nucleus [25]. Improving our understanding of platelet biology is a prerequisite for the development of new therapeutic strategies aimed at exploiting the huge potential of these small cells.

We here describe a new approach that is suitable for imaging in 'real-time' quality parameters in viable platelets. For this purpose, we visualized the mitochondrial membrane potential of platelets by adding the potentiometric dye, TMRM, to the platelets. In addition, TMRM, WGA and cellpermeable Rhod-2 were used to visualize platelet morphology and calcium levels.

Mitochondria have long been known to act as energy producers. Besides this essential role, mitochondria are also wellknown for their central role in regulating cell death. Many death stimuli converge on these organelles to cause a release of apoptogenic factors. This mitochondrial response is also coupled with an interruption in energy production and changes in calcium homeostasis [26].

A recently published study examined the mitochondrial membrane potential of apheresis-derived platelets (un) treated for pathogen reduction using another potentiometric dye called JC-1. With this stain, polarized mitochondria appear red and depolarized green. Analysis of JC-1 fluorescence was performed using FACS analysis [27]. As also shown in our study, platelet storage causes a slight decrease in mitochondrial functionality. Pathogen reduction treatment, however, had no significant effect on mitochondrial potential. 
A rise in intracellular calcium as well as a decrease in mitochondrial function $[28,29]$ can lead to enhanced exposure of PS on the outer membrane of platelets, which is known to result in their phagocytosis and unwanted procoagulant and inflammatory activities after transfusion [30].

Although platelet refrigeration is currently not an alternative to the current blood banking practice of storing platelets at room temperature, cryopreservation of platelets potentially offers advantages, such as the prevention of bacterial growth, that justify the ongoing research for optimized freeze/resuspension media, freeze rates or temperatures. As routinely applicable assays that can evaluate platelet function in vivo and in vitro and predict platelet vitality and hemostatic efficacy are still lacking, real-time live confocal microscopy might be a valuable tool because it sheds the light necessary to visualize platelet vitality. This has been shown, for example, for the combination of WGA and TMRM that in individual platelets visualizes the most basic prerequisite for platelet vitality, i.e. the ability to produce ATP, which is indispensable for their proper function.

Lectins are proteins with various specificities for the sugar residues commonly found in glycoproteins as well as glycolipids. The lectin WGA binds to sialic acid, $\mathrm{N}$-acetylglucosamine and $\mathrm{N}$-acetylgalactosamine. Already more than 3 decades ago, lectins such as WGA were bonded to gold granules in order to visualize the localization of cell surface glycoconjugates on platelets. Those studies used scanning and transmission electron microscopy [31] for analysis. In this study we use fluorescence-labeled WGA in combination with live confocal imaging to visualize platelet morphology.

The fast data acquisition (15 $\mathrm{min})$ and the high precision allowing visualization of even single organelles in living viable platelets meet the requirements for fast and efficient monitoring of platelet quality after their isolation and/or storage.

Besides affording the possibility to monitor living cells, such a procedure permits very fast assessment of platelet quality (in less than $30 \mathrm{~min}$ ) in comparison to classical antibody staining procedures that normally take at least $2 \mathrm{~h}$. We anticipate that the information obtained with real-time live confocal microscopy will ultimately aid clinical progress in the field of platelet quality assessment.

The study of mitochondrial membrane potential using TMRM proved to be very useful with respect to early identification of nonviable platelets. Taking into consideration the many other live fluorescent stains, their combination with a powerful live confocal imaging system promises to be of great value for better platelet quality assessment after isolation and during storage.

The method presented here might also be a means of addressing one of the current central questions regarding platelet biology: 'Are circulating platelets different populations, each predisposed to a certain response, or does the local acti- vating environment determine their ultimate fate [32]?' Using live stains in combination with confocal microscopy allows individual platelets to be discriminated and is therefore probably one of the best suited approaches for studying intrinsic differences among platelets. Previous studies have already shown that individual platelets within a thrombus can markedly differ in morphology as well as in their surface characteristics. In order to determine their activation state within a thrombus, platelets are often stained for specific surface markers such as fibrin(ogen), PAC1, P-selectin or annexin A5 [33]. Such staining procedures take several hours, while live stain confocal microscopy shows platelet morphology, mitochondrial activity or calcium content within $15 \mathrm{~min}$. We therefore believe our method to provide an additional tool that complements the existing methods for analyzing platelet vitality.

In addition, real-time live confocal microscopy might also be a valuable tool for the study of hereditary platelet disorders. Therefore, our future studies will test its applicability for the diagnosis of platelet disorders characterized by specific morphological platelet aberrations.

The asymmetric phospholipid distribution in the plasma membrane of platelets is energy-dependent. When activated, platelets lose membrane lipid asymmetry, which causes PS at the outer surface of platelets to be exposed. Nearly 3 decades ago, Bevers et al. $[34,35]$ demonstrated that the asymmetric orientation of phospholipids in platelets is lost following the influx of calcium during their activation. Since PS promotes blood coagulation, these findings suggested a critical role for PS in thrombosis. Both energy and calcium play a central role in regulating phospholipid asymmetry. Defects in this delicate balance bring on disorders such as Scott syndrome, a bleeding disorder caused by defective scrambling of membrane phospholipids [36-38].

The recent recognition of platelet heterogeneity could have implications for the development of antiplatelet medications that are directed to only one of the subpopulations [39]. Therefore, a method such as the one we here present, which is well-suited for identifying differences between individual platelets under different conditions and within a few minutes, promises to be of great help in experiments addressing such issues of platelet heterogeneity.

\section{Acknowledgements}

The authors thank BMA Christian Reif for excellent technical assistance.

\section{Disclosure}

The authors declared no conflict of interest. 


\section{References}

1 Springer DL, Miller JH, Spinelli SL, Pasa-Tolic L, Purvine SO, Daly DS, Zangar RC, Jin S, Blumberg $\mathrm{N}$, Francis CW, Taubman MB, Casey AE, Wittlin SD, Phipps RP: Platelet proteome changes associated with diabetes and during platelet storage for transfusion. J Proteome Res 2009;8:2261-2272.

2 Blajchman MA, Goldman M, Baeza F: Improving the bacteriological safety of platelet transfusions. Transfus Med Rev 2004;18:11-24.

$\checkmark 3$ Cauwenberghs S, van PE, Curvers J, Akkerman JW, Heemskerk JW: Hemostatic and signaling functions of transfused platelets. Transfus Med Rev 2007;21:287-294.

4 Murphy S, Gardner FH: Platelet storage at 22 degrees C; metabolic, morphologic, and functional studies. J Clin Invest 1971;50:370-377.

5 Murphy S, Gardner FH: Effect of storage temperature on maintenance of platelet viability - deleterious effect of refrigerated storage. N Engl J Med 1969:280:1094-1098.

6 Mondoro TH, Vostal JG: Cold temperatures reduce the sensitivity of stored platelets to disaggregating agents. Platelets 2002;13:11-20.

7 Vostal JG, Mondoro TH: Liquid cold storage of platelets: a revitalized possible alternative for limiting bacterial contamination of platelet products. Transfus Med Rev 1997;11:286-295.

8 Solheim BG: Pathogen reduction of blood components. Transfus Apher Sci 2008;39:75-82.

$\checkmark$ Seghatchian J, Krailadsiri P: The platelet storage lesion. Transfus Med Rev 1997;11:130-144.

10 Kaufman J, Spinelli SL, Schultz E, Blumberg N, Phipps RP: Release of biologically active CD154 during collection and storage of platelet concentrates prepared for transfusion. J Thromb Haemost 2007;5:788-796.

11 Clauser S, Cramer-Borde E: Role of platelet electron microscopy in the diagnosis of platelet disorders. Semin Thromb Hemost 2009;35:213-223.

12 Sweeney JD, Arduini A: L-carnitine and its possible role in red cell and platelet storage. Transfus Med Rev 2004;18:58-65.

13 Mitchell P, Moyle J: Estimation of membrane potential and $\mathrm{pH}$ difference across the cristae membrane of rat liver mitochondria. Eur J Biochem 1969;7:471-484.

14 Solaini G, Sgarbi G, Lenaz G, Baracca A: Evaluating mitochondrial membrane potential in cells. Biosci Rep 2007;27:11-21.
Solaini G, Sgarbi G, Lenaz G, Baracca A: Evaluating mitochondrial membrane potential in cells. Biosci Rep 2007;27):11-21.

16 Hermann M, Pirkebner D, Draxl A, Margreiter R, Hengster P: 'Real-time' assessment of human islet preparations with confocal live cell imaging. Transplant Proc 2005;37:3409-3411.

17 Kuznetsov AV, Troppmair J, Sucher R, Hermann M, Saks V, Margreiter R: Mitochondrial subpopulations and heterogeneity revealed by confocal imaging: possible physiological role? Biochim Biophys Acta 2006;1757:686-691.

18 Kuznetsov AV, Hermann M, Troppmair J, Margreiter R, Hengster P: Complex patterns of mitochondrial dynamics in human pancreatic cells revealed by fluorescent confocal imaging. J Cell Mol Med 2010;14:417-425.

19 Nakano A: Spinning-disk confocal microscopy - a cutting-edge tool for imaging of membrane traffic Cell Struct Funct 2002;27(5):349-355.

20 Nussbaumer W, Allersdorfer D, Grabmer C, Rheinschmidt M, Lin L, Schonitzer D, Lass-Florl C: Prevention of transfusion of platelet components contaminated with low levels of bacteria: a comparison of bacteria culture and pathogen inactivation methods. Transfusion 2007;47:1125-1133.

21 Seghatchian J, Krailadsiri P: The platelet storage lesion. Transfus Med Rev 1997;11:130-144.

22 Khan SY, Kelher MR, Heal JM, Blumberg N, Boshkov LK, Phipps R, Gettings KF, McLaughlin NJ, Silliman CC: Soluble CD40 ligand accumulates in stored blood components, primes neutrophils through CD40, and is a potential cofactor in the development of transfusion-related acute lung injury. Blood 2006;108:2455-2462.

23 Springer DL, Miller JH, Spinelli SL, Pasa-Tolic L, Purvine SO, Daly DS, Zangar RC, Jin S, Blumberg N, Francis CW, Taubman MB, Casey AE, Wittlin SD, Phipps RP: Platelet proteome changes associated with diabetes and during platelet storage for transfusion. J Proteome Res 2009;8:2261-2272.

24 Silliman CC, Khan SY, Ball JB, Kelher MR, Marschner S: Mirasol Pathogen Reduction Technology ${ }^{\circledR}$ treatment does not affect acute lung injury in a two-event in vivo model caused by stored blood components. Vox Sang 2010;98:525-530.

25 Schwertz H, Koster S, Kahr WH, Michetti N, Kraemer BF, Weitz DA, Blaylock RC, Kraiss LW, Greinacher A, Zimmerman GA, Weyrich AS: Anucleate platelets generate progeny. Blood 2010;115: 3801-3809.
26 Hermann M, Kuznetsov A, Maglione M, Smigelskaite J, Margreiter R, Troppmair J: Cytoplasmic signaling in the control of mitochondrial uproar? Cell Commun Signal 2008;6:4.

27 Picker SM, Schneider V, Oustianskaia L, Gathof BS: Cell viability during platelet storage in correlation to cellular metabolism after different pathogen reduction technologies. Transfusion 2009;49: 2311-2318.

28 Smeets EF, Comfurius P, Bevers EM, Zwaal RF: Calcium-induced transbilayer scrambling of fluorescent phospholipid analogs in platelets and erythrocytes. Biochim Biophys Acta 1994;1195: 281-286.

29 Sweeney JD, Arduini A: L-carnitine and its possible role in red cell and platelet storage. Transfus Med Rev 2004;18:58-65.

30 Seghatchian J, Krailadsiri P: The platelet storage lesion. Transfus Med Rev 1997;11:130-144.

31 Nurden AT, Horisberger M, Savariau E, Caen JP: Visualisation of lectin binding sites on the surface of human platelets using lectins adsorbed to gold granules. Experientia 1980;36:1215-1217.

32 Munnix IC, Cosemans JM, Auger JM, Heemskerk JW: Platelet response heterogeneity in thrombus formation. Thromb Haemost 2009;102:1149-1156.

33 Munnix IC, Cosemans JM, Auger JM, Heemskerk JW: Platelet response heterogeneity in thrombus formation. Thromb Haemost 2009;102:1149-1156.

34 Bevers EM, Comfurius P, van Rijn JL, Hemker HC, Zwaal RF: Generation of prothrombin converting activity and the exposure of phosphatidylserine at the outer surface of platelets. Eur J Biochem 1982;122:429-436.

35 Bevers EM, Comfurius P, Zwaal RF: Changes in membrane phospholipid distribution during platelet activation. Biochim Biophys Acta 1983;736:57-66.

36 Zwaal RF, Schroit AJ: Pathophysiologic implications of membrane phospholipid asymmetry in blood cells. Blood 1997;89:1121-1132.

37 Zwaal RF, Comfurius P, Bevers EM: Scott syndrome, a bleeding disorder caused by defective scrambling of membrane phospholipids. Biochim Biophys Acta 2004;1636:119-128.

38 Zwaal RF, Comfurius P, Bevers EM: Surface exposure of phosphatidylserine in pathological cells. Cell Mol Life Sci 2005;62:971-988.

39 Munnix IC, Cosemans JM, Auger JM, Heemskerk JW: Platelet response heterogeneity in thrombus formation. Thromb Haemost 2009;102:1149-1156. 